SOCRATES

\title{
SOCRATES 6 (Synopsis of Cochrane Reviews applicable to emergency services)
}

\author{
P Gilligan, A Taylor, A Khan, J Jones, H Law, J Brenchley, D Hegarty, M Shepherd, G Lumsden, \\ G Kitching
}

o $\mathrm{n}$ this the sixth article of the SOCRATES series we present our synopses of reviews from the Cochrane Database of Systematic Reviews relating to orthopaedics and trauma that the working party felt were of particular relevance to emergency medicine practitioners. The methods of our review and the rationale for the forming the SOCRATES working party are as have previously been published.

\section{CONSERVATIVE INTERVENTIONS FOR TREATING DISTAL RADIAL FRACTURES IN ADULTS \\ Background}

Distal radial fractures are common in the emergency department population. The most suitable method of management is not clearly defined and will be influenced by many considerations. This review set out to determine the most appropriate treatment for fractures of the distal radius in skeletally mature people.

\section{Results}

Twenty nine studies of disappointing quality were identified involving 3199 patients. Treatment options reviewed included: above versus below elbow plaster, different durations of plaster immobilisation, supination versus pronation, brace versus plaster cast, bandage versus plaster or brace, different cast materials; and for displaced fractures: manipulation versus no manipulation and delayed versus immediate manipulation. There is insufficient evidence to deduce robust conclusions on any of these.

\section{SOCRATES says}

Practitioners should use a cost effective treatment, which they are familiar with at present.

A Handoll HHG, Madhok R. Conservative interventions for treating distal radial fractures in adults (Cochrane Review). In: The Cochrane Library, Issue 4. Oxford: Update Software, 2000.

\section{PREOPERATIVE TRACTION FOR FRACTURES OF THE PROXIMAL FEMUR \\ Background}

Skeletal or skin traction has been standard practice in some departments following an acute proximal femur fracture. It is thought to reduce pain and assist the reduction of the fracture. Disadvantages include difficulties in nursing the patient and local complications at the application site. There is debate whether traction has any effect on femoral head circulation.

\section{Results}

Five randomised trials of moderate quality were identified involving a total of 635 patients. The four trials comparing traction with no traction revealed no evidence of benefit in relief of pain, ease or quality of fracture reduction at subsequent surgery. One trial compared skin with skeletal traction-no difference was shown in efficacy, though skeletal traction was more painful and costly.

\section{SOCRATES says}

There is no evidence to support the use of skin or skeletal traction in the pre-operative management of patients with proximal femur fractures.

A Parker MJ, Handoll HHG. Pre-operative traction for fractures of the proximal femur (Cochrane Review). In: The Cochrane Library, Issue 4. Oxford: Update Software, 2000.

INTERVENTIONS FOR PREVENTING AND TREATING STRESS FRACTURES AND STRESS REACTIONS OF THE BONES OF THE LOWER LIMBS IN YOUNG ADULTS

\section{Background}

Spontaneous activity-associated lower limb pain, particularly in the region of the tibia, is a significant problem in military recruits and in athletes.

The objectives of this review were to evaluate the evidence from controlled trials of treatments and programmes for the prevention or management of lower limb stress fractures and stress reactions of bone in active young adults.

\section{Results}

Nine studies investigating prevention and three studies of treatment were identified. The quality of the studies was generally poor.

Prevention: Five trials examined the use of insoles and found them to be of benefit. No benefit was found with reduction in frequency and intensity of running/marching and oral calcium supplements.

Treatment: Significant reduction in time to recommencing training after diagnosis was demonstrated in both studies evaluating the use of a pneumatic brace. Low power laser application was of no benefit.

\section{SOCRATES says}

Rehabilitation after tibial stress fracture is aided by the use of pneumatic bracing. The use of shock absorbing insoles may reduce the incidence of stress fractures.

$\Delta$ Gillespie WJ, Grant I. Interventions for preventing and treating stress fractures and stress reactions of the bones of the lower limbs in young adults (Cochrane Review). In: The Cochrane Library, Issue 4. Oxford: Update Software, 2000.

\section{MEDICAL ANTI-SHOCK TROUSERS (PNEUMATIC ANTI-SHOCK GARMENTS) FOR CIRCULATORY SUPPORT IN PATIENTS Background}

To quantify the effect on mortality and morbidity of the use of medical anti-shock trousers (MAST)/pneumatic anti-shock garments (PASG) in patients following trauma. 


\section{Results}

Two randomised trials involving 1202 patients, of which data was available for 1075 patients. The relative risk of death with MAST was 1.13 (95\% CI 0.97 TO 1.32). Duration of hospitalisation was longer in the MAST treated group.

\section{SOCRATES says}

There is no evidence to suggest that MAST/PASG application reduces mortality, length of hospitalisation or length of ICU stay in trauma patients and it is possible that it may increase these.

A Dickinson K, Roberts I. Medical anti-shock trousers (pneumatic anti-shock garments) for circulatory support in patients with trauma (Cochrane Review). In: The Cochrane Library, Issue 1. Oxford: Update Software, 2001.

\section{ULTRASOUND THERAPY FOR ANKLE SPRAINS Background}

Acute ankle sprains are extremely common and may be associated with long term complications of pain and functional disability. Ultrasound (US) therapy is used in many musculoskeletal conditions, and in the laboratory at least, promotes cellular metabolic rate and increased viscoelastic properties of collagen. The objective of this review was to determine whether ultrasound is more effective than reference treatments (placebo, no treatment, or other types of interventions) in patients with acute ankle sprains. Outcome measures included general recovery, improvement of pain relief, swelling, functional disability, and range of movement.

\section{Results}

Four randomised or pseudo randomised controlled trials were identified involving 514 patients. Three compared US therapy with sham US (transducer applied to skin but no US delivered). These failed to show any statistically significant benefit. All studies were relatively small and of only modest methodological quality.

\section{SOCRATES says}

Ultrasound therapy is of no benefit in the treatment of acute ankle sprains.

A Van der Windt, Van der Heijden, Van der Berg, et al. Ultrasound therapy for acute ankle sprains (Cochrane Review). In: The Cochrane Library, Issue 4. Oxford: Update Software, 2000.

\section{NERVE BLOCKS (SUBCOSTAL, LATERAL CUTANEOUS, FEMORAL, TRIPLE, PSOAS) FOR HIP FRACTURE

Hip fracture refers to a fracture of the femur from the head to a level $5 \mathrm{~cm}$ below the greater trochanter. These injuries are common in the elderly population and cause significant pain. There is often a reluctance to give high doses of opiate or non-steroidal analgesics to these patients due to risk of side effects. Various nerve blocks have been described in order to reduce pain. This review was undertaken to determine if nerve blocks are effective in relieving pain after hip fractures.

\section{Results}

Six trials were identified involving 229 patients. Only one trial examined the use of a femoral nerve block on admission to hospital, all other trials involved peri-operative insertion. All studies documented a reduction in the quantity of other analgesic requirements. The numbers involved are too small to reveal a clinical benefit from this reduction. No study reported complications of the technique.

\section{SOCRATES says}

Nerve blocks are a useful adjunct in pain management in patients with proximal femoral fractures.

A Parker MJ, Griffiths R, Appadu BN. Nerve blocks (subcostal, lateral cutaneous, femoral, triple, psoas) for hip fractures (Cochrane Review). In: The Cochrane Library, Issue 4. Oxford: Update Software, 2000.

\section{INTERVENTIONS FOR TREATING PLANTAR HEEL PAIN Background}

Plantar heel pain syndrome or plantar fasciitis is estimated to affect $10 \%$ of the general population at some time. Little is known of the underlying disease process or clinical course. It is often self limiting, but can be a source of impairment and disability over months or even years in some patients. This review looked at the evidence from controlled trials for the effectiveness of interventions for the treatment of plantar heel pain.

\section{Results}

Eleven randomised controlled trials were included involving 465 patients. Treatments investigated included heel pads, steroid injections, ultrasound therapy, iontophoresis with topical steroid, electron beam therapy, low dose extracorporeal shock wave therapy, and night splints. There was no significant benefit from injected corticosteroids or from orthotic devices. There is limited evidence of benefit of topical steroid administered by iontophoresis.

\section{SOCRATES says}

There is little evidence to support many of the accepted treatments of plantar fasciitis.

A Crawford F, Atkins D, Edwards J. Interventions for treating plantar heel pain (Cochrane Review). In: The Cochrane Library, Issue 4. Oxford: Update Software, 2000.

\section{Conclusion}

In this article the SOCRATES working party have summarised the reviews we felt were relevant to emergency practitioners in the Cochrane Database of Systematic Reviews relating to orthopaedics and trauma. In the next issue we will present our synopses of reviews relating to analgesia.

\section{ACKNOWLEDGEMENTS}

We would like to thank Dr Richard Hardern and the staff of the Postgraduate Medical Library at the General Infirmary at Leeds for their support and technical advice in the preparation of this paper.

\section{Authors' affiliations \\ P Gilligan, A Taylor, A Khan, J Jones, H Law, J Brenchley, M Shepherd, G Lumsden, G Kitching, Specialist Registrars in Emergency Medicine, The Yorkshire Rotation, UK \\ D Hegarty, General Practitioner, Leeds, UK \\ Competing interests: none declared}

Correspondence to: Dr P Gilligan, 1 Far Moss, Alwoodley, Leeds, Yorkshire, England, UK. LS17 7NU; hegartydeirdre@ireland.com 